\title{
FOREST ABOVE GROUND BIOMASS ESTIMATION AND FOREST/NON-FOREST CLASSIFICATION FOR ODISHA, INDIA, USING L-BAND SYNTHETIC APERTURE RADAR (SAR) DATA
}

\author{
M. Suresh ${ }^{\text {a*, T. R. Kiran Chand }}{ }^{\text {a, }}$, Rakesh Fararoda a ${ }^{\text {a }}$ C.S.Jha ${ }^{\text {a }}$, V.K. Dadhwal ${ }^{\text {b }}$ \\ ${ }^{a}$ Forestry and Ecology Group, National Remote Sensing Centre, Hyderabad- 500037 \\ (suresh202020m, trkchand, rakesh.rocky630, chandra.s.jha)@gmail.com, \\ ${ }^{\mathrm{b}}$ National Remote Sensing Centre, Hyderabad- 500037 - dadhwalvk@ hotmail.com
}

Commission VIII, WG VIII/7

KEY WORDS: Above ground biomass, SAR, backscatter coefficient, Texture, Support Vector Machine Classification,

\section{EXTENDED ABSTRACT}

Tropical forests contribute to approximately $40 \%$ of the total carbon found in terrestrial biomass. In this context, forest/non-forest classification and estimation of forest above ground biomass over tropical regions are very important and relevant in understanding the contribution of tropical forests in global biogeochemical cycles, especially in terms of carbon pools and fluxes. Information on the spatio-temporal biomass distribution acts as a key input to Reducing Emissions from Deforestation and forest Degradation Plus (REDD+) action plans. This necessitates precise and reliable methods to estimate forest biomass and to reduce uncertainties in existing biomass quantification scenarios.

The use of backscatter information from a host of allweather capable Synthetic Aperture Radar (SAR) systems during the recent past has demonstrated the potential of SAR data in forest above ground biomass estimation and forest / nonforest classification.

In the present study, Advanced Land Observing Satellite (ALOS) / Phased Array L-band Synthetic Aperture Radar (PALSAR) data along with field inventory data have been used in forest above ground biomass estimation and forest / non-forest classification over Odisha state, India. The ALOSPALSAR $50 \mathrm{~m}$ spatial resolution orthorectified and radiometrically corrected $\mathrm{HH} / \mathrm{HV}$ dual polarization data (digital numbers) for the year 2010 were converted to backscattering coefficient images (Schimada et al., 2009).

The tree level measurements collected during field inventory (2009-'10) on Girth at Breast Height (GBH at $1.3 \mathrm{~m}$ above ground) and height of all individual trees at plot (plot size 0.1 ha) level were converted to biomass density using species specific allometric equations and wood densities. The field inventory based biomass estimations were empirically integrated with ALOS-PALSAR backscatter coefficients to derive spatial forest above ground biomass estimates for the study area.
Further, The Support Vector Machines (SVM) based Radial Basis Function classification technique was employed to carry out binary (forest-non forest) classification using ALOSPALSAR HH and HV backscatter coefficient images and field inventory data. The textural Haralick's Grey Level Cooccurrence Matrix (GLCM) texture measures are determined on HV backscatter image for Odisha, for the year 2010. PALSAR $\mathrm{HH}, \mathrm{HV}$ backscatter coefficient images, their difference (HHHV) and HV backscatter coefficient based eight textural parameters (Mean, Variance, Dissimilarity, Contrast, Angular second moment, Homogeneity, Correlation and Contrast) are used as input parameters for Support Vector Machines (SVM) tool. Ground based inputs for forest / non-forest were taken from field inventory data and high resolution Google maps.

Results suggested significant relationship between HV backscatter coefficient and field based biomass $\left(R^{2}=0.508\right.$, $\mathrm{p}=0.55$ ) compared to $\mathrm{HH}$ with biomass values ranging from 5 to $365 \mathrm{t} / \mathrm{ha}$. The spatial variability of biomass with reference to different forest types is in good agreement. The forest / nonforest classified map suggested a total forest cover of 50214 $\mathrm{km}^{2}$ with an overall accuracy of $92.54 \%$. The forest / non-forest information derived from the present study showed a good spatial agreement with the standard forest cover map of Forest Survey of India (FSI) and corresponding published area of $50575 \mathrm{~km}^{2}$. Results are discussed in the paper 


\section{INTRODUCTION}

Forests play an important role in balancing the Earth's $\mathrm{CO} 2$ supply and exchange, acting as a key link between the atmosphere, geosphere, and hydrosphere; therefore, monitoring forest biomass at local to global scales has become a challenging issue in the context of climate change. Tropical forests contain about $40 \%$ of carbon found in terrestrial biomass (Dixon et al., 1994; Phillips et al., 1998; Watson et al., 2000). A precise quantification of above ground biomass (AGB) and producing accurate and high resolution up to date forest cover maps in tropical forests are the international efforts to avoiding deforestation and associated emissions. The issue of Reducing Emissions from deforestation and Degradation plus (REDD+) in developing countries has been initiated (Achard et al., 2007; Gibbs et al., 2007; http://unfccc.int/resource/docs/2005/cop11/eng/05.pdf). Forest carbon pools consist of trunks, branches, leaves, litter, dead wood, roots and soil carbon. In tropical forests worldwide, about $50 \%$ of the total carbon is stored in above ground biomass and $50 \%$ is stored in the top $1 \mathrm{~m}$ of the soil. Because of this, precise and reliable methods are needed for estimating loss of forest cover, land cover change and monitoring forest carbon stocks at national level to assess the economic benefits.

Tropical forests are often difficult to access on the ground because of this satellite observations and measurements could become the primary source for monitoring AGB and producing forest maps. Optical remote sensing has proved to be useful for estimating deforestation and detecting secondary vegetation but it may be obstructed clouds and smokes for most of the times in tropical region and is insensitive to biomass growth. Space borne Synthetic Aperture Radar (SAR) are active systems that transmit microwave energy at wavelengths ranging from $1-100 \mathrm{~cm}$ (X band to $\mathrm{P}$ band). They are weather and daylight independent. This is very advantageous in tropical regions, which are often covered by clouds. Moreover, radar signal are sensitive to moisture content and vegetation structure properties which may help to forest types (Saatchi et al., 1997; Salas et al., 2002; Neumann et al., 2010).

Polarized SAR at L-band (e.g., ALOS/PALSAR) has been successfully used for estimating AGB (Wolter et al., 2011; Santoro et al., 2009; Cartus et al., 2012; Robinson et al., 2013) and regional land cover classification (Nicolas Longépé et al., 2011) due to the high sensitivity of the backscattered signal at L-bands to forest structure, probably because of strong interactions with tree trunks and branches. In this context, we used ALOS PALSAR $50 \mathrm{~m}$ dual polarization (HH/HV) mosaic data for forest above ground biomass (AGB) estimation and forest/non-forest (FNF) classification for the Odisha, India for the year 2010 .

The main objective of this research is to investigate the potential of L-band dual polarization SAR (PALSAR) data for state level biomass estimation by using regression method and forest/non-forest classification by using Support Vector Machine (SVM) supervised classification method.

\section{STUDY AREA AND DATA}

Study area selected for both objectives (Forest AGB estimation and FNF classification) of this research is the Odisha, it is an eastern state of India and which lies between $17.49 \mathrm{~N}$ latitude to
22.34N latitude and 81.27E longitude to $87.29 \mathrm{E}$ longitude (Fig.1). It has an area of $155,707 \mathrm{~km}^{2}$ and extends for 800 kilometres from north to south and 500 kilometres from east to west. Its coastline is 480 kilometre long. There are three major seasons- summer (March-June), Rainy season (July-September) and the winter (October-February) and has tropical climate. It is warm almost throughout the year in the western districts of Sundergarh, Sambalpur, Baragarh, Bolangir, Kalahandi and Mayurbhnj with maximum temperature hovering between 40 $46^{\circ} \mathrm{C}$ and in winter, it is intolerably cool. In coastal districts, the climate is equable but highly humid and sticky. The summer maximum temperature ranges between $35-40^{\circ} \mathrm{C}$ and the low temperatures are usually between $12-14^{0} \mathrm{C}$. The average rainfall is $150 \mathrm{~cm}$, experienced as the result of south west monsoon during July-September. The state experiences small rainfall from the retreating monsoon in the months of OctoberNovember, January and February are dry. The study area, thickly covered by forests both of the tropical moist deciduous type as well as tropical dry deciduous. The hills, plateaus and isolated areas of the north eastern part of the state are covered by the tropical moist deciduous forests whereas the second types of the forests are located in the southwest region of the state. Some of the trees which grow in abundance in Odisha are bamboo, teak, rosewood, sal, piasal, sanghvan and haldi (Roy et. al., 2012).

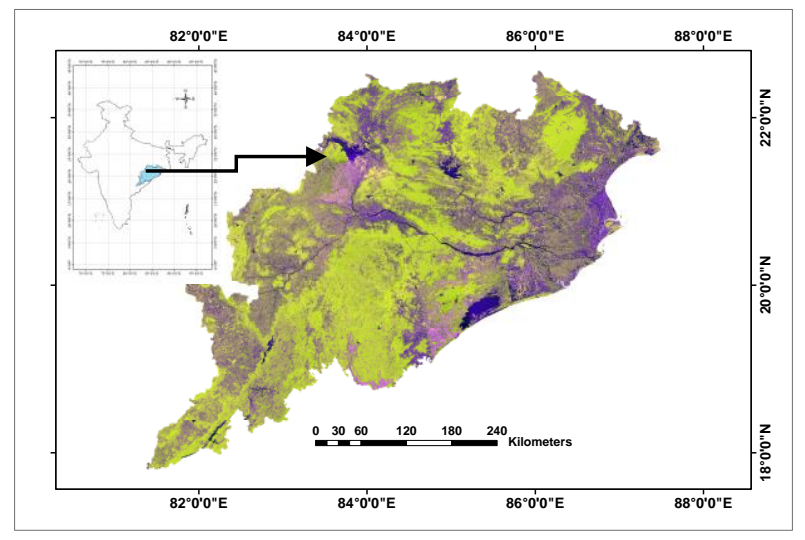

Fig.1 False colour composite (HH HV HH-HV) image of study area

Table 1: ALOS PALSAR mosaic data details

\begin{tabular}{|l|l|l|l|l|l|l|}
\hline Sensor mode & $\begin{array}{l}\text { Polar } \\
\text { izati } \\
\text { on }\end{array}$ & $\begin{array}{l}\text { Off } \\
\text { nadir } \\
\text { angle }\end{array}$ & $\begin{array}{l}\text { Inciden } \\
\text { ce } \\
\text { range }\end{array}$ & $\begin{array}{l}\text { Swath } \\
\text { width }\end{array}$ & $\begin{array}{l}\text { Pass } \\
\text { designa } \\
\text { tion }\end{array}$ & $\begin{array}{l}\text { Cove } \\
\text { rage }\end{array}$ \\
\hline $\begin{array}{l}\text { Fine Beam } \\
\text { Dual } \\
\text { polarization }\end{array}$ & $\begin{array}{l}\text { HH+ } \\
\text { HV }\end{array}$ & $34.3^{0}$ & $\begin{array}{l}36.6^{0} \sim \\
40.9^{0}\end{array}$ & $70 \mathrm{~km}$ & $\begin{array}{l}\text { Ascend } \\
\text { ing }\end{array}$ & $\begin{array}{l}\text { Glob } \\
\text { al }\end{array}$ \\
\hline
\end{tabular}

In this study we used the PALSAR 50-m Orthorectified Mosaic Product HH (horizontally transmitted and horizontally received) and $\mathrm{HV}$ (horizontally transmitted and vertically received) polarizations has been used and data contains HH/HV backscatter images (DN values). ALOSPALSAR 50-m mosaic product product details shown in table 1. 


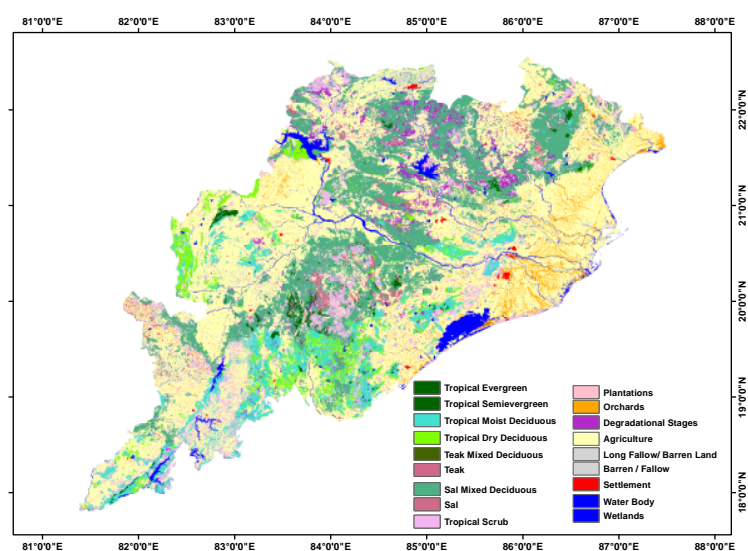

Figure 2. Land cover map of Odisha for 2005-06. It showing main land cover classes contained in the study area.

\section{METHODOLOGY}

The methodology (Fig.3) of this study comprises four parts i.e. Ground sampling data collection, SAR image processing, biomass estimation and FNF SVM classification.

\subsection{Ground sampling data collection}

Field inventory data was collected as part of ISRO GBP National Carbon Project in 2009-10 and planned a common inventory design over the entire country with the sample plot size of 0.1 ha. Sample sites were carefully selected to ensure adequate coverage of all major forest types and forest density classes. Forest inventory parameters (Diameter at breast height (DBH), tree height, species, tree density and forest types) were collected from sample sites. Tree level measurements were converted to biomass density using regions and species specific volume equations and wood densities. Forest inventory parameters and their relationship with tree volume has been used to assess plot biomass (table2) using the allometric model developed for this study area.

Ground sampling pints for forest / non-forest classes were taken from field inventory data and high resolution Google maps. Forest sampling locations are taken from forest field inventory data (as explained above). The Non-forest locations are collected using Google maps and taken from Agriculture, Urban/settlement, water bodies and Scrub land areas and considered as one class (Non-forest) because the main aim of this effort is forest and non-forest classification. The number of training and test samples used for the study area is given in Table 3 .

Table 2: Summary of AGB measured within all the sample plots.

\begin{tabular}{lllll}
\hline $\begin{array}{l}\text { sample } \\
\text { size (n) }\end{array}$ & $\begin{array}{l}\text { Minimum } \\
(\mathrm{t} / \mathrm{ha})\end{array}$ & $\begin{array}{l}\text { Maximum } \\
(\mathrm{t} / \mathrm{ha})\end{array}$ & $\begin{array}{l}\text { Mean } \\
(\mathrm{t} / \mathrm{ha})\end{array}$ & $\begin{array}{l}\text { Standard } \\
\text { deviation (t/ha) }\end{array}$ \\
\hline 183 & 11.60 & 293.01 & 61.35 & 47.94 \\
\hline
\end{tabular}

\subsection{Calculation of backscattering coefficient}

The dual-polarization PALSAR $50 \mathrm{~m}$ mosaic data set was as 16bit Unsigned Integer data with digital number (DN) ranging from 0 to 65,535 for each of polarization. The backscatter coefficient $\left(\sigma_{0}\right)$, or Normalized Radar Cross Section (NRCS), for $\mathrm{HH}$ and $\mathrm{HV}$ polarization components was obtained from following equation:

$$
\sigma_{0}(d B)=10 \times \log _{10} D N^{2}+C F
$$

Where $\mathrm{DN}=$ digital number, and $\mathrm{CF}=$ sensor calibrated constant, set at $-83.0 \mathrm{~dB}$.

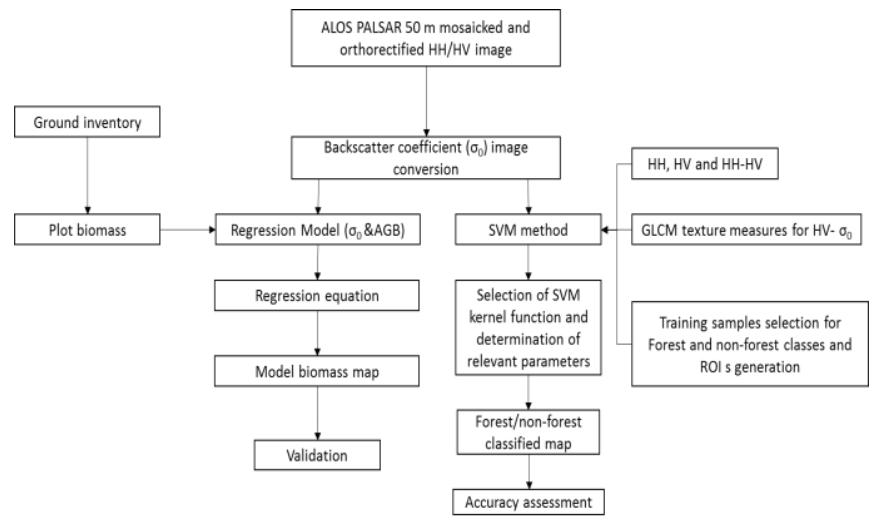

Fig. 3. Overall methodology flow chart

The converted backscattering coefficient images $\left(\sigma_{0} d B\right), \mathrm{HH} / \mathrm{HV}$ are used for biomass modelling and texture measurement analysis.

\subsection{Biomass modelling and mapping}

In this research we have used linear regression models with log transformation of field biomass data for establishing relationship between ALOS PALSAR backscattering coefficient $\left(\sigma_{0}\right)$ and field biomass (AGB). Before applying regression analysis between PALSAR backscatter and ground sampling data, an average of $3 \times 3 \mathrm{HH} / \mathrm{HV}$ backscatter pixels was used for reducing GPS geo location error. The PALSAR HH and HV $\sigma_{0}$ values are extracted at corresponding locations of measured AGB of sampling plots. Both variables ( $\sigma_{0}$ and AGB) of each plot were correlated to produce empirical models in which the best correlation was selected and used for AGB prediction for whole study area. The predicted AGB was presented in a thematic layer showing the distribution of AGB $t \mathrm{ha}^{-1}$ over the study area.

\subsection{Extraction of texture features on $\mathrm{HV}$ backscattering image}


Textural information has proven to be efficient for natural target monitoring even if no unique solution has been used to incorporate such information into a classification method (Saatchi et al., 2000; Simard et al., 2000; Kuplich et al., 2005). Two-point statistics such as the grey-level co-occurrence features are among the most commonly used tool for texture characterization (Nicolas Longépé et al., 2011). The Grey Level Co-occurrence Matrix (GLCM) is a statistically based method of obtaining textural information from remotely sensed imagery of all types. The GLCM is computed from a relative displacement vector $(d, \Theta)$, which is based on the spatial distribution of grey level pairs of pixels separated by a distance (d) in a particular direction $(\Theta)$. From this information, a number of textural measurements can be derived (Hralick, 1979) out which eight texture features are frequently used i.e. Mean, Variance, Entropy, Variance, Contrast, Dissimilarity, Homogeneity, Correlation, Second Moment and Mean, all of which have been shown to be useful in discriminating between tropical forest types (Podest et al., 2002). A detailed description of each texture measure can be found in Haralick (1979). Eight image texture measures were extracted for HV backscatter image. Selecting an appropriate window size for texture analysis is critical, as small window sizes often exaggerate differences, while large window sizes cannot effectively extract texture due to smoothing ( $\mathrm{Lu}$ and Batistella, 2005). Rather than deciding upon a particular window size to generate texture measures in advance, all eight texture measures were generated for a window size $3 \times 3$ pixels. Texture was then derived for four commonly used directions within the window $\left(45^{\circ}, 90^{\circ}, 135^{\circ}\right.$ and $0^{\circ}$ ), with the central pixel value derived from integrating all four values. To reduce computational effort the GLCM matrix was constructed using a 64 grey level quantization, since high image quantization levels can generate sparse GLCMs, which may compromise the accuracy of the probability estimates for GLCM and, thus any derived texture measures (Bijlsma, 1993).

All eight texture measures on $\mathrm{HV}$ and $\mathrm{HH}, \mathrm{HV}, \mathrm{HH}-\mathrm{HV}$ backscatter images were used as input band layers for SVM forest/non-forest classification.

Textural features to be selected by the SVM based methodology for the features selection

\begin{tabular}{|c|c|c|c|c|}
\hline \multirow{2}{*}{$\begin{array}{l}\text { PALS } \\
\text { AR } \\
\text { chann } \\
\text { el }\end{array}$} & \multicolumn{2}{|c|}{$\begin{array}{l}\text { Image } \\
\text { quantization }\end{array}$} & \multirow{2}{*}{$\begin{array}{l}\text { GLCM } \\
\text { computati } \\
\text { on } \\
\text { window } \\
\text { size }\end{array}$} & \multirow[t]{2}{*}{ Haralick's features } \\
\hline & method & $\begin{array}{l}\text { Numbe } \\
\mathrm{r} \text { of } \\
\text { levels }\end{array}$ & & \\
\hline HV & $\begin{array}{l}\text { Histogr } \\
\text { am } \\
\text { equaliz } \\
\text { ation }\end{array}$ & 64 & $3 \times 3$ & $\begin{array}{l}\text { Mean, Dissimilarity, } \\
\text { Entropy, Second } \\
\text { moment, } \\
\text { Homogeneity, } \\
\text { Contrast } \\
\text { Variance }\end{array}$ \\
\hline
\end{tabular}

\subsection{Support Vector Machine (SVM)}

SVM was initially proposed to construct an optimal separating hyper plane when data are linearly separable. The hyper plane is constructed to achieve the maximum margins between training samples from different classes based on support vectors, which is defined as the nearest vectors from each class to the hyper plane. When data cannot be linearly separated, kernel function was introduced to project the original data to higher dimensional space, in which an optimal separating hyper plane can be derived. When misclassification of some training samples cannot be avoided, a parameter $\mathrm{C}$ is introduced to indicate the trade-off between penalty of misclassification against simplicity of the hyper plane. A smaller $\mathrm{C}$ value indicates more tolerance of misclassification. It was reported that SVM method is largely influenced by the parameters of kernel function and penalty parameter $\mathrm{C}$ but not type of kernel function (Vapnik, 1995). In the past, three types of kernel functions were often used: polynomial function, Radial Basis Function (RBF) and sigmoid function. In this study, we used the $\mathrm{RBF}$ as the kernel function given the fact that it is independent of data size and dimensionality while achieving good performance. Specific form of the RBF is provided in the following equation,

$\mathrm{K}\left(x_{i}, x_{j}\right)=\exp \left(-\gamma\left\|x_{i}-x_{j}\right\|^{2}\right), \gamma>0$

In which $\gamma$ is a critical parameter that represents the spatial extent that a particular training sample can reach. The smaller the value of $\gamma$, the further distance it can influence.

In this study, we developed a scheme to combine a grid search method and cross validation (CV) to determine the optimal values of $\gamma$ and $\mathrm{C}$ when the RBF kernel is applied. The grid search method aims to alternate $\gamma$ and $\mathrm{C}$ in an efficient way, in which an initial lower bound of $\gamma$ and $\mathrm{C}$ is first defined. Then, $\gamma$ and $\mathrm{C}$ will independently increase on an exponential pace at each step until $\gamma$ and $\mathrm{C}$ reach their upper bound (Hsu, Chang, and Lin 2003). Associated with each pair of $\gamma$ and $C$ values, a CV is carried out in the following manner. First, all the training samples are equally split into several folds. Then, an iterative process is introduced to treat one fold as the validation set while the remaining as training ones. A classification was conducted every time when the training and test samples alternated. Then, an average accuracy (over all accuracy) of classification can be calculated from all the training and test sets in the iteration. Consequently, the optimal $\gamma$ and $\mathrm{C}$ values are those that yield the highest average classification accuracy.

Table 3: Samples used for forest/non-forest classes

class

Forest Non-forest

Training samples

31

103

Testing samples

71

100

Support Vector Machine performs supervised classification on sigma naught images plus GLCM texture measures to identify the class associated with each ground ROIs pixel. In this study eight texture bands (Mean, Variance, Dissimilarity, Contrast, Correlation, Homogeneity, Entropy and Second moment) and two backscattering images ( $\mathrm{HH}, \mathrm{HV}$ ), one difference image (HH-HV) were used as the input bands for 
SVM. These eleven band combination improved the accuracy of forest-non forest classification. In this study 102 forest samples and 203 non-forest samples are randomly (shown in fig 4) selected for SVM training and accuracy assessment. These sample data locations are overlay on the ALOS PALSAR bands and converted as the 'region of interest' (ROI) for forest and non-forest class's tools provided by ENVI version 5. The total forest, non-forest ROI's selected for training is 31 and 103 respectively and for the validation 71 and 100 are taken from different locations. Accuracy validation of the classified maps was based on the independent validation samples as presented above.

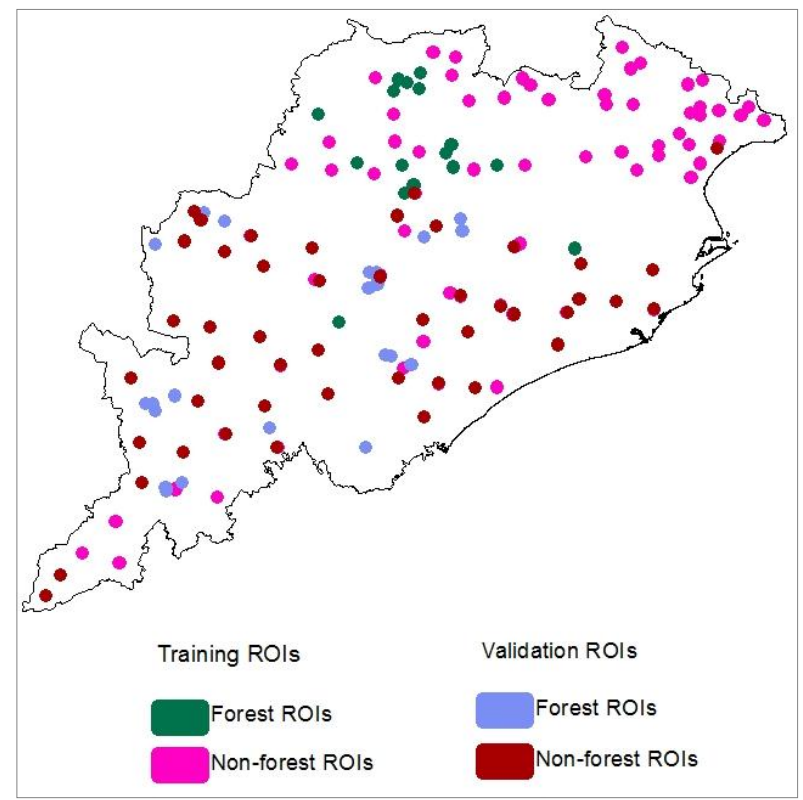

Fig. 4. The spatial distribution of ground sampling locations over India. The Regions of Interest (ROIs) used for the algorithm training and results validation.

\section{RESULTS AND ANALYSIS}

\subsection{Biomass modelling and validation}

The major forest types found in all sampling plots were dry deciduous and moist deciduous. The number of sample plots are 183 and the biomass range of these plots between 11.6 and 293 $\mathrm{t} / \mathrm{ha}$. The majority of the plots measured AGB were $<100 \mathrm{t} / \mathrm{ha}$, the distribution of the AGB within all the sample plots is summarized in Table2 and depicted in Fig.5.

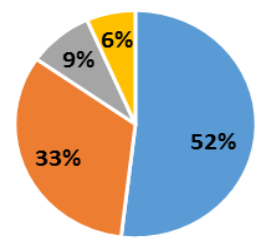

$A G B(t / h a)=1-50=50-100=100-150=>150$

Fig. 5. The percentage of sample plots in distributed AGB
The extracted $\mathrm{HH}$ and $\mathrm{HV} \sigma_{0}(\mathrm{~dB})$ variables were correlated with the AGB that was obtained from the sample plots. Both of these, HV polarization backscattering coefficient showing significant response with AGB up to $150 \mathrm{t} / \mathrm{ha}$, after that response is very less and constant. The HV backscatter gave the highest correlation with a coefficient of determination $\left(\mathrm{R}^{2}\right)$ of 0.508 as compared with HH. Scatter plots showing correspondences of AGB with $\mathrm{HH}$ and $\mathrm{HV}$ variables are shown in Fig. 6 and summary of models produced is listed in Table 4. The correlation analysis indicates that the AGB has a logarithmic relationship with the variables.
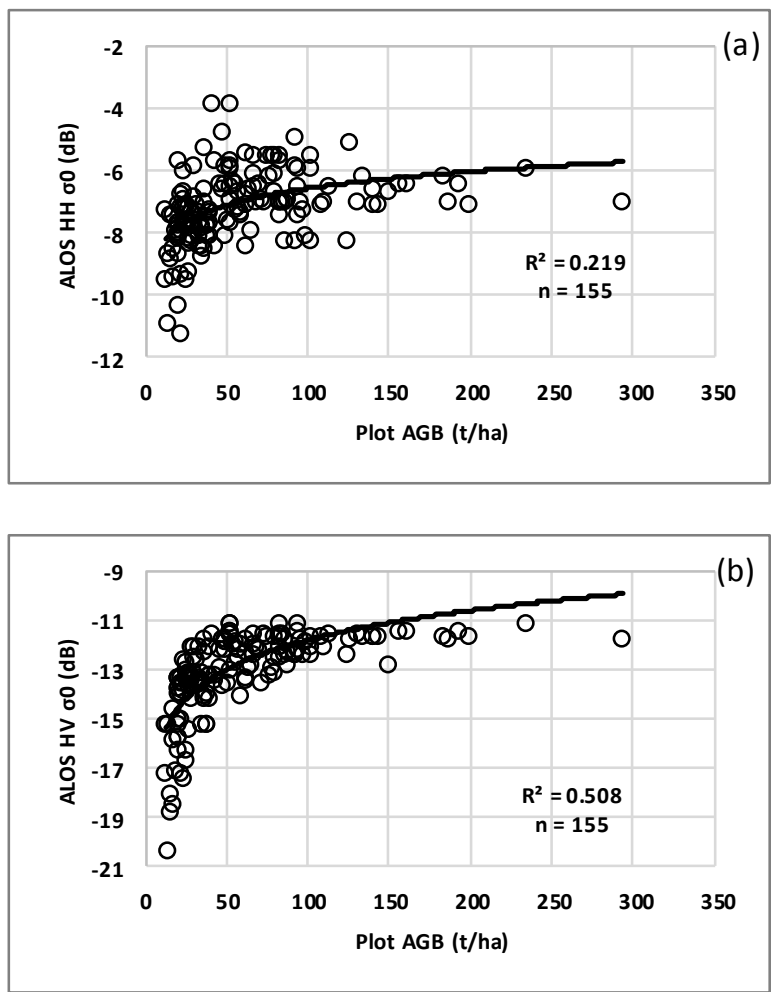

Fig. 6. Relationships between PALSAR $\mathrm{HH}$ and $\mathrm{HV}$ backscattering coefficient versus plot biomass values shown in (a) and (b) respectively.

Table 4. Logarithmic correlations and coefficients of determination $\left(\mathrm{R}^{2}\right)$ of $\mathrm{AGB}$ and image variables of L-band PALSAR polarizations.

\begin{tabular}{lll}
\hline Variable & Model & $\mathrm{R}^{2}$ \\
\hline $\mathrm{HH}$ & $\mathrm{y}=0.7818 \ln (\mathrm{x})-10.167$ & 0.219 \\
$\mathrm{HV}$ & $\mathrm{y}=1.7383 \ln (\mathrm{x})-19.782$ & 0.508 \\
\hline
\end{tabular}

Based on the correlation analysis, the backscatter of $\mathrm{HV}$ polarization was selected as the AGB prediction model as it gave the best $\mathrm{R}^{2}$ compared to $\mathrm{HH}$. The $\mathrm{HV}$ backscatter of all corresponding plots in the study area ranged from -20.39 to $11.07 \mathrm{~dB}$, with a mean of $-13.09 \mathrm{~dB}$. The trend line indicates that the biomass component has a logarithmic correlation to the backscatter. The relationship is asymptotic, increasing rapidly at lower AGB levels (i.e. up to $100 \mathrm{t} / \mathrm{ha}$ ) but constant towards 
higher AGB levels. The scatter plots clearly show that the HV backscatter gave a good response with AGB at $<100 \mathrm{t} / \mathrm{ha}$. A relatively low AGB (i.e. $<100$ t/ha) was correlated well with low backscatter (i.e. -19 up to $-12 \mathrm{~dB}$ ). The HV backscatter was similar as the AGB increased levelling at around $-12 \mathrm{~dB}$. This confirmed that the saturation level of AGB in deciduous forest was at $\sim 100-150 \mathrm{t} / \mathrm{ha}$.

The saturated backscatter value depends mainly on the orientation, size and dielectric constant distribution of the backscattering and forward scattering functions of the individual scatterers (Chen et al., 2009). SAR backscattering will start to saturate when the above ground biomass level reaches at 150 t/ha (Held et al., 2003; Quinones et al., 2004). This means that if the AGB increases to more than $150 \mathrm{t} / \mathrm{ha}$, the backscatter will become almost constant. This was consistent with the findings observed in the study; the backscatter increased rapidly as the biomass increased from $11 \mathrm{t} / \mathrm{ha}$ but the sensitivity reduced slightly when biomass exceeded $90 \mathrm{t} / \mathrm{ha}$.

Referring to Table 5, the root mean square error (RMSE) of estimation model was calculated based on the validation plots that were established in the study area. A total of 28 validation plots, which supported an AGB between 11.60 and $219.76 \mathrm{t} / \mathrm{ha}$ were used to validate the estimates. An absolute accuracy - a measure of the error between a derived/predicted biomass from satellite image and the actual biomass measured on the ground - was calculated for predicted model (Table 5). The absolute accuracy is expressed as the RMSE, such that:

RMSE $=\sqrt{\left[\frac{1}{n} \sum_{i=1}^{n}\left(\left(A G B_{o}-A G B_{p}\right)-\mu\right)^{2}\right]}$

Where

$\mathrm{n} \quad$ the number of validation plots

$\mathrm{AGB}_{0}$ measured biomass at plot $\mathrm{i}$

$\mathrm{AGB}_{\mathrm{p}}$ derived/predicted biomass at position $\mathrm{i}$

$\mu \quad$ Average of biomass difference

The observed RMSE for all validation plots is \pm 46.54 t/ha. To further investigate factors contributing to this RMSE, a scatter plot of observed AGB against the predicted AGB was produced by using the same validation plots as illustrated in Fig. 7. The propagation of errors were found to be significantly higher at an AGB >150 t/ha and became larger as the amount of biomass increased.

Table 5: Used model equation for predicted biomass map

\begin{tabular}{llll}
\hline $\begin{array}{l}\text { Variabl } \\
\text { e }\end{array}$ & Model & $\mathrm{R}^{2}$ & $\operatorname{RMSE}( \pm \mathrm{t} / \mathrm{ha})$ \\
\hline $\mathrm{HV}$ & $\mathrm{AGB}=2163.3 * \mathrm{e}^{0.2922 * \mathrm{HV}}$ & 0.508 & 46.54 \\
\hline
\end{tabular}

ALOS PALSAR HH, HV and HH-HV bands and texture features were used as input to the SVM method. The eight GLCM texture features were extracted with window size $3 \times 3$ and quantization level 64 on the HV backscattering image, for this combination we carried out classification and got good overall accuracy. We select $\gamma=1$ and $\mathrm{C}=10$ as it provides less penalty to misclassification of training samples and thus be more generalized. It is confirmed by previous studies (Nicolas Longépé et al., 2011; Le Wanga et al., 2014). 
Table 6: Confusion Matrix for forest/non-forest classified map

$$
\begin{aligned}
& \text { Overall Accuracy }=92.54 \% \\
& \text { Kappa Coefficient }=0.84
\end{aligned}
$$

\begin{tabular}{|l|l|l|l|}
\hline Class & Forest & Non-forest & User Acc. (\%) \\
\hline Forest & 83.15 & 0.79 & 98.69 \\
\hline Non-forest & 16.85 & 99.21 & 89.22 \\
\hline Prod. Acc. (\%) & 83.15 & 99.21 & \\
\hline
\end{tabular}

We tested the classification performance of SVM with produced final forest/non-forest classified map. The confusion matrix for produced forest/non-forest classified map over the whole study area is shown in Table 6 . This table summarizes the accuracy associated with forest and non-forest classes. It is clearly shows that the SVM method based on ALOSPALSAR data and its textural features have the good capability in forest and non-forest discrimination with an overall accuracy of 92.54\% and kappa coefficient of 0.84 . Furthermore, this method yielded the highest producer's accuracy $(83.15 \%)$ and user's accuracy $(98.69 \%)$ in forest classification. It should be noted that the areas used for training and the validation were prepared independently. The final map of forest and non-forest for 2010 is shown in Fig.9.

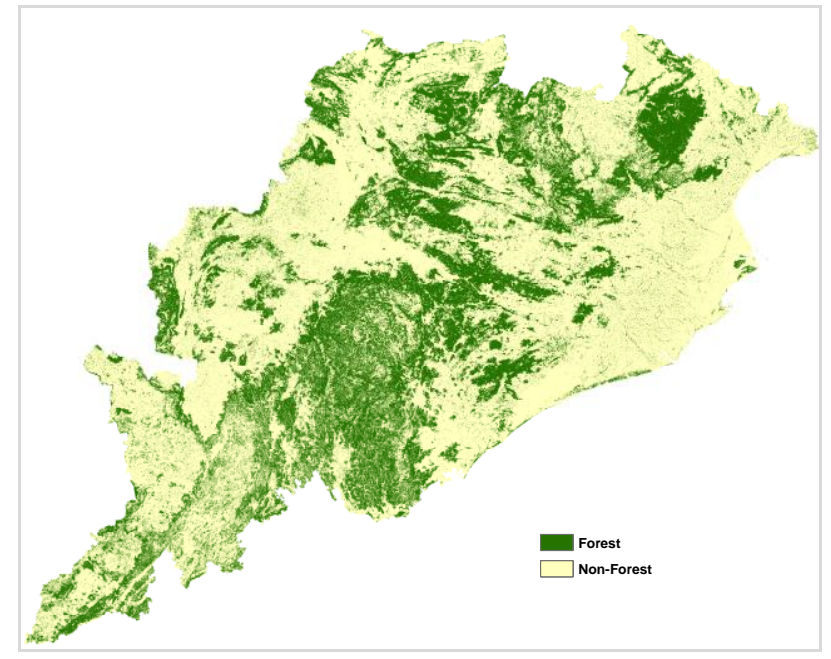

Fig. 9. PALSAR SVM based Forest-Non forest classified map for 2010 of Odisha. Overall classification accuracy is greater than $90 \%$.

\section{DISCUSSION AND CONCLUSION}

The produced spatial above ground biomass ranges has to be confirmed from previous results for the study area and more comparison analysis has to be done in future. The relation between SAR backscatter and ground biomass has to be improved more because the coefficient of determination from present result 0.508 is not that much good. This study confirmed that with the help of empirical relation for ALOSPALSAR HV backscatter and AGB, we can estimate above ground biomass accurately up to 150 t/ha and above this limit the PALSAR signal is not good response for AGB.
The final forest / non-forest classified map estimated the total forest cover of $50214 \mathrm{~km}^{2}$ with an overall accuracy of $92.54 \%$. The comparison with the standard forest cover map of Forest Survey of India (FSI) and corresponding published area of $50575 \mathrm{~km}^{2}$, ALOSPALSAR data underestimate the area with around $361 \mathrm{~km}^{2}$. Using ALOSPALSAR data the SVM methodology some cases considering scrub land, plantations and trees outside forest are classifying under forest class. This remarkable misclassification will be reduced in further improvement of forest/non-forest cover map. Present estimated forest/non-forest map with overall accuracy $92.54 \%$ is well agreement with previous published results that ALOSPALSAR and LANDSAT based forest/non-forest map with overall accuracy $92.4 \%$ (Wayne et al., 2010).

\section{ACKNOWLEDGEMENTS}

The authors acknowledge JAXA for providing 50m ALOS PALSAR HH and HV mosaics.

\section{REFERENCES}

Achard, F., DeFries, R., Eva, H., Hansen, M., Mayaux, P., 2007.Pan-tropical monitoring of deforestation, Environmental. Research Letters 2(4), pp. 045022-1045022-11.

Cartus, O., Kellndorfer, J., Rombach, M., Walker, W., 2012. Mapping canopy height and growing stock volume using Airborne Lidar, ALOS PALSAR and Landsat ETM+. Remote Sensing. 4, 3320-3345.

Dixon, R.K., Brown, S., Houghton, R.A., Solomon, A.M., Trexler, M.C., 1994. Carbon pools and flux of global forest ecosystems Science, 263, 185-190.

Gibbs, H., Brown, S., O’Niles, J., 2007. Monitoring and estimating tropical forest carbon stocks: Making REDD a reality. Environmental Research Letters 2(4), pp. 045023 1-045023-13.

Haralick, R., Shaunmugam, K., 1973. Textural features for image classification. IEEE Transactions Systems Man Cybernetics, SMC-3(6), pp. 610-621.

Hralick, R. M., 1979. Statistical and structural approaches to texture. IEEE, 67, pp. 786-805.

Kuplich T., Curran, P., 2005. Relating SAR image texture to the biomass of regenerating tropical forest. International Journal of Remote Sensing, 26(21), pp. 4829-4854.

Le Wanga, b., Sai Zhanga, 2014. Incorporation of texture information in a SVM method for classifying salt cedar in western China. Remote Sensing Letters, 5(6),501-510.

Lu, D., 2005. Above ground biomass estimation using Landsat TM data in the Brazilian Amazon. International Journal of Remote Sensing, 26(12).

Neumann, M., Ferro-Famil, L., Reigber, A., 2010. Estimation of forest structure, ground, and canopy layer characteristics from multibaseline polarimetric interferometric SAR data. IEEE Transactions Geoscience Remote Sensing. 48(3), pp. 1086-1104.

Nicolas Longépé, Preesan Rakwatin, Osamu Isoguchi, Masanobu Shimada, Fellow, IEEE, Yumiko Uryu, and Kokok Yulianto, 2011. Assessment of ALOS PALSAR 50 
m Orthorectified FBD Data for Regional Land Cover Classification by Support Vector Machines. IEEE TRANSACTIONS ON GEOSCIENCE AND REMOTE SENSING, 49(6).

Phillips, O.L., Malhi Y., Higuchi, N., Laurance, W.F., Nunez, P.V., et al., 1998. Changes in the carbon balance of tropical forests: evidence from long-term plots Science, 282: $439-442$

Podest, E., Saatchi, S., 2002. Application of Multiscale Texture in Classifying JERS-1 Data over Tropical Vegetation. International Journal of Remote Sensing, 23(7) pp. 1487-1506.

Reducing Emissions from Deforestation in Developing Countries: Approaches to Stimulate Action-Draft Conclusions Proposed by the President, United Nations Framework Convention on Climate Change, 2005. [Online]. Avaialble: ttp://unfccc.int/resource/docs/2005/cop11/ eng/102.pdf

Robinson, C., Saatchi, S., Neumann, M., Gillespie, T., 2013. Impacts of spatial variability on aboveground biomass estimation from L-band radar in a temperate forest. Remote Sensing, 5, 1001-1023.

Roy, P.S., Kushwaha, S.P.S., Murthy, M.S.R., Roy A., Kushwaha, D., Reddy, C.S., Behera, M.D., Mathur, V.B., Padalia, H., Saran, S., Singh, S., Jha, C.S. \& Porwal, M.C. 2012. Biodiversity characterisation at Landscape Level: National Assessment. Indian Institute of Remote Sensing, Dehradun, India, pp. 140, ISBN 81-901418-8-0

Saatchi, S., Nelson, B., Podest, E., Holt, J., 2000. Mapping land cover types in Amazon basin using $1 \mathrm{~km}$ JERS-1 mosaic. International Journal of Remote Sensing, 21(6/7), pp. 1201-1234.

Saatchi, S., Soares, J., 1997. Mapping deforestation and land use in Amazon rainforest using SIR-C imagery. Remote Sensing of Environment, 59(2), pp. 191-202.
Salas, W., Ducey, M., Rignot, E., Skole D., 2002. Assessment of JERS-1 SAR for monitoring secondary vegetation in amazonia: II. Spatial, temporal, and radiometric considerations for operational monitoring. International Journal of Remote Sensing. 23(7), pp. 13811399.

Santoro, M., Fransson, J.E., Eriksson, L.E., Magnusson, M., Ulander, L.M., Olsson, H., 2009. Signatures of ALOS PALSAR L-band backscatter in Swedish forest. IEEE Transactions on Geoscience and Remote Sensing. 47, 4001-4019.

Shimada, Masanobu., Isoguchi, Osamu., Tadono, Takeo., Isono, Kazuo., 2009. PALSAR Radiometric and Geometric Calibration. IEEE Transactions on Geoscience and Remote Sensing, 47(12), pp. 3915-3932.

Simard, M., Saatchi, S., De Grandi, G., 2000. The use of decision tree and multiscale texture for classification of JERS-1 SAR data over tropical forest. IEEE Transactions on Geoscience and Remote Sensing, 38(5), pp. 2310-2321.

Walker, Wayne S., Claudia, M., Stickler, Josef M., Kellndorfer, Katie, M., Kirsch, Daniel., Nepstad C., 2010. Large- Area Classification and Mapping of Forest and Land Cover in the Brazilian Amazon: A Comparative Analysis of ALOS/PALSAR and Landsat. IEEE Journal of Selected topics in Applied Earth Observations and Remote Sensing, 3(4).

Watson, R.T., Noble, I.R., Bolin, B., Ravindranath, N.H., Verardo. D.J., et al. (eds) (2000). Land use, land-use change, and forestry A special report of IPCC Cambridge University Press, Cambridge

Wolter, P.T.; Townsend, P.A., 2011. Multi-sensor data fusion for estimating forest species composition and abundance in northern Minnesota. Remote Sensing of Environment. 115, pp. 671-691. 